TP Periodica Polytechnica

Chemical Engineering

58(2), pp. 111-116, 2014

DOI: $10.3311 / P P c h .7082$

Creative Commons Attribution (i)

RESEARCH ARTICLE

\section{Evaluation of Microwave Vacuum Drying Combined with Hot-Air Drying and Compared with Freeze- and Hot-Air Drying by the Quality of the Dried Apple Product}

\author{
Sándor Ferenczi ${ }^{1 *} /$ Bálint Czukor $^{1} /$ Zsuzsanna Cserhalmi $^{1}$
}

RECEIVED 11 October 2013; Accepted After ReVIsion 4 March 2014

\begin{abstract}
In this study, combined microwave vacuum drying (MVD) with hot-air drying was evaluated, and then compared with hotair drying and freeze drying, by the quality of the created product. The aim was to show that MVD is a strong quality competitor with the conventional hot-air drying and the widely used, but expensive freeze drying. For raw material, Jonathan apple was used. The combined microwave vacuum drying consists of two steps, the hot-air pre-drying, and then the microwave vacuum drying. The MVD was made with a unique batch drying system.

Chemical, (total phenolic compounds, free radical-scavenging activity, aromatic content) physical (hardness) and consumer-related (organoleptic, and microbiological) properties were measured as quality parameters.

The results show that quality of the product made by MVD combined with hot-air pre-drying is higher than hot-air dried ones. By most of the measured quality parameters, microwave vacuum drying also provided higher quality product than freeze drying.
\end{abstract}

\section{Keywords}

Microwave vacuum drying - hot-air drying - freeze drying · drying · apple

\footnotetext{
${ }^{1}$ National Agricultural Research and Innovation Centre, Food Science Research Institute, Division of Technology and Food Chain analysis Herman Ottó út 15., H-1022 Budapest, Hungary

"Corresponding author email: $\underline{\text { sferenczi@,cfri.hu }}$
}

\section{Introduction}

A widespread and simple method for preserving fruits and vegetables is drying. Due to novel, energy-efficient and rapid technologies, creation of new dried products, with unique characteristics, excellent rehydration rate, sensory preferred properties and high nutrition value becomes possible. Most commonly used technologies for drying are hot-air drying, freeze drying, osmotic dehydration, microwave-, and vacuum drying. The conventional thermal methods, including hot-air drying, vacuum drying, and freeze-drying, result in low drying rates in the falling rate period of drying $[2,16]$. Using the conventional and new methods in different combinations results advantageous properties, for example higher drying rate and increased quality product.

Microwave vacuum drying (MVD) is one of the newest varieties of mild food manufacturing technologies. It is a rapid and efficient dehydration method, which yields unique characteristics, improved product appearance and quality, compared to conventionally dried products. [14] On national and international levels, there is intensive research and development activity for more wide-ranging application of MVD technology. The reason of the active interest in the use of this drying technology is the rapid drying and the special texture of the end products. The authors have been dealing with this technology since 2010, determining the optimal parameters of MVD combined with hot-air drying for creating a less-burned and low bulk density product. [4,5]

The aim of this present work was to study the chemical, physical and consumer-related differences between the products of hot-air drying, freeze drying and combined MVD. Chemical properties, such biologically active- and aromatic compounds, physical-rheological properties, and consumer-related properties, such as organoleptic-, and microbiological properties were investigated.

\subsection{Drying rate}

At foodstuff, the simultaneous usage of microwaves and vacuum causes faster drying rate compared to conventional drying methods, because of the same direction of heat-, and mass transfer. [12] 
The process of MVD can be divided into three periods. At the beginning, the microwave radiation almost completely turns into heat, causing continuously warming sample. The warming keeps going until the boiling point of the water, which is determined by the ambient pressure. The evaporation in this period is negligible. Compared to the hot-air drying, this phase is much more rapid. The next period is the intensive drying. The temperature of the sample is approximately constant, while the energy of radiation is being consumed by the moisture evaporation. During hot-air drying, the drying rate decreases continuously, while the MVD has no, or minimal drying rate reduction. The third period is characterized by decreasing intensity drying. The drying rate decreases, while also the more strongly bound water evaporates. In the conventional hot-air drying method, this is the most time-consuming period, taking away two-thirds of the total drying time. MVD has two significant advantages in this period: most of the moisture leaves in the isothermal period, and the diffusion of the evaporated moisture inside the sample is much faster than the diffusion of liquid moisture. [17]

During MVD, the drying rate is affected by the total irradiated energy, the applied vacuum value, the sample mass in the vacuum chamber and their relations. High energy input and low pressure increases the rate of mass transfer, thus the drying rate, while more weight of sample per treatment decreases the drying rate. $[10,13]$

\subsection{Quality of product}

Compared to hot-air drying, the improved quality is achieved by the combination of microwave energy and vacuum. The electromagnetic microwave radiation penetrates the interior of the food, where it is converted to thermal energy and causes rapid warming. However, the vacuum reduces the boiling point of water, keeping the product temperature low, as well as creating a pressure gradient that enhances the drying rate. The microwave vacuum drying is less time-consuming, compared to air-and freeze-drying, which takes up to several days. [12] The microwave radiation is being applied cyclically, with moderately strong vacuum, which results in better product quality and energy efficiency. The unique, crispy, open cellular structure of the dried product, related to MVD is created by an expansive force by the in situ vaporization of water. This product is suitable for direct consumption as a smack, or can be consumed after storage and rehydration. The texture is created by the overheated moisture, which caused by microwave heating, and reduced boiling temperature by the vacuum. Steam is generated inside the material, which creates inner pressure, thus the puffing of the product. During drying, this process is somewhat controllable, because the strength of the structurekeeping force depends on the evaporation rate (thus indirectly on the energy input) and the pressure of the vacuum chamber. This puffing phenomenon occurs more intensively when the MVD process is preceded by hot-air drying.
Other advantage of the MVD over traditional drying methods is the greater retention of bioactive components of foods, for example antioxidants or vitamins, which are easily inactivated by oxidation or thermal degradation.

Attention should be paid to the smooth heat treatment and the apropriate drainage of the generated vapor. Their absence could result in unfavorable burning. The phenomenon starts with browning, presumably the Maillard-reaction, but finally results burnt, inedible products. The burning always starts from the inner material, reaching the surface only in a few cases, makes it hard to sense. The burning of the product can be avoided by moving the sample during drying, reducing its size, or reducing the intensity of the microwave energy.

\subsection{Combined microwave vacuum drying with hot-air pre-drying}

During drying, fruits and vegetables have a critical point of dry mass content. If the moisture content is removed by conventional drying until this point, where only the free water leaves the sample, then the quality parameters of the product does not change. So, the combination of hot-air-, and microwave vacuum drying is more energy- and cost-efficient, and creates better quality product than using the technologies alone. [3,7]

\section{Materials and methods}

\subsection{Material}

As raw material, Jonathan apple was used, because of its pleasant aroma and prosperous puffing tendency. The apples have been grown at Zsámbék (Hungary), and were purchased at the local market (Budapest, Hungary). The ovary of the apple was removed and then cut into $8 \mathrm{~mm}$ thick slices.

\subsection{Drying Methods}

\subsubsection{Hot-air drying}

The prepared apple slices was hot-air dried in laboratoryscale drying equipment until full removal of moisture content. The L-MIM 320 type dryer has a volume of $400 \mathrm{dm}^{3}$. The applied velocity and temperature was $9 \mathrm{~m} / \mathrm{s}$ and $60^{\circ} \mathrm{C}$. The drying process took about 14-20 hours, depending on the humidity level of ambient air and the initial moisture content of apple.

\subsubsection{Combined microwave vacuum drying with hot-air drying}

After the preparation, the sample was hot-air dried in the above-mentioned laboratory-scale drying equipment, and then microwave vacuum-dried for $30 \%$ and $2 \%$ moisture content (w.b.) respectively.

The microwave vacuum drying equipment has a cylindrical stainless steel vacuum chamber, with a conical dome for better vapor removal. The samples are hold in a rotary teflon tray. Microwaves are generated by two, 850W nominal efficiency magnetrons. The vacuum is kept constant at 50 mbar by a 

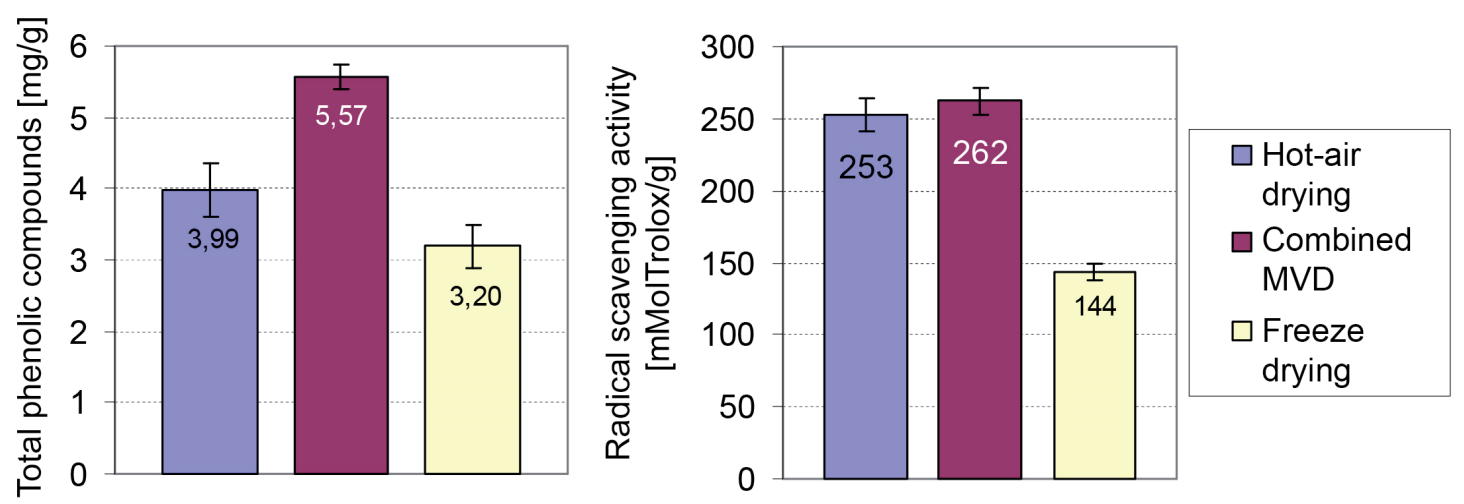

Fig. 1. Biologically active compounds of dried samples

vacuum pump, connected to the heat exchanger for vapor condensation. The cooling water for the heat exchanger is cooled by a compressor and kept circulating by a pump. For each treatment, 200 grams of pre-dried apple was dried. Intensive radiation was used in the beginning of the treatment, and then the intensity was continuously reduced. The radiation (active) and relaxation (passive) time was equal.

\subsubsection{Freeze-drying}

Freeze drying was done with a Leybold-Heraeus Lyovac GT2 type freeze drying equipment. The prepared raw apple is refrigerated to $-20^{\circ} \mathrm{C}$ and then $100 \mathrm{~g}$ was put to 4 heated sample-holding trays. The heating power is $50 \mathrm{~W}$ per tray. The vacuum value was set to $60 \mathrm{~Pa}$. The drying process took for about 36 hours, until the vacuum wasn't affected by the sublimated vapor. The moisture content of the samples was $2 \%$ (w.b.).

\subsection{Measurement methods}

\subsubsection{Total phenolic compounds}

The measurement of total phenolic compound was made with Folin-Ciocalteu reagent by Singleton et al. [11].

\subsubsection{Radical scavenging activity}

The measurement of radical scavenging activity was made with DDPH free radical by Yamaguchi et al. [15].

\subsubsection{Aromatic compounds}

The measurement of aromatic compounds in the samples was done with GC method. The applied device and detector was HP 5890, HP 5971 mass selective detector, RH-5 ms+ Colonna with $30 \mathrm{~m}$ length, $0,25 \mathrm{~mm}$ inner diameter and $0,25 \mu \mathrm{m}$ film thickness. Carrier gas was helium. The applied temperature profile was $50{ }^{\circ} \mathrm{C} 4$ minutes, $4{ }^{\circ} \mathrm{C} /$ minute $120^{\circ} \mathrm{C}$, splitless injection, 1 minute, detector $260^{\circ} \mathrm{C}$.

The identification of the compounds was made with Wiley 275 library. The literary Kovats-index was indicated. [8]

\subsubsection{Hardness measurement}

The rheological test of the dried samples was done with a Lloyd Material Testing Instruments LR5KPlus type tenderometer, applied with TG84 type adapter. For the recording of data, Nexygen 4.0 software was used. The samples was held in a square-shaped container, perforated at the bottom and was pushed by a surface of $0,01 \mathrm{~m}^{2}$ adapter. With constant pushing velocity, the device measures the mechanical resistance of the sample by the function of compression distance. The compression limit was $50 \mathrm{~mm}$.

\subsubsection{Organoleptic properties}

Sensory test of the samples was done by a civilian group of 11 members by the following 5-point scale criterions: appearance, color, consistency, taste. The samples were compared by the criterions alone, and also by their averages.

\subsubsection{Microbiological examination}

Standard Salmonella, Listeria monocytogenes, aerobic plate count, fungi, yeast, E. coli and coliforms tests was performed on the dried products. Their water activity was measured by Novasina LabMasteraw device on $25^{\circ} \mathrm{C}$, with triplicates each. The device measures the electrolyte resistance of the samples. No sample preparation needed.

\section{Results and discussion}

\subsection{Biologically active compounds}

A similar trend can be observed in the total phenolic compound and radical scavenging activity (Fig. 1). The combined MVD samples had the most amount of biologically active compounds, although the radical scavenging activity versus the hotair dried samples was not significant. Both values of biologically active compounds of freeze dried samples were inferior. This result is contrary to common view, because freeze drying is known to be a mild drying technology, but in some cases, the antioxidant activity in freeze dried samples were lower, than 
Tab. 1. Aromatic compounds of dried samples

\begin{tabular}{ccc|cc}
\hline $\begin{array}{c}\text { retention time } \\
{[\mathrm{s}]}\end{array}$ & compound & $\begin{array}{c}\text { Kovats-index OV } \\
101\end{array}$ & Freeze drying & Combined MVD \\
\hline 2.544 & 1-butanol & 655 & 11,2 \\
6.948 & 1-hexanol & 858 & 14,2 \\
11.402 & 6-methyl-5-hepten-2-on & 968 & 17,4 & 10 \\
12.496 & hexyl-acetate & 1012 & 9 & 6,7 \\
18.774 & unknown & & 24,2 & 46,5 \\
19.571 & butyl-hexanoate & 1175 & & 20,6 \\
19.734 & alpha-farnezene & & 58,1 & 4,7 \\
21.307 & hexil-2-methylbutyrate & 1224 & \\
\hline
\end{tabular}

conventional $100^{\circ} \mathrm{C}$ air dried samples [9]. The higher values of biological active components at hot-air drying could be explained by the measuring method, which might be sensitive to compounds, formed by thermal treatment. Changa et al. [1] and Hossain et al. [6] found that total phenolics were higher in air-dried samples, than freeze dried ones. The explanation of the result was the liberation of phenolic compounds from the matrix during the process. This paper's result shows the advantageous effect of combined MVD on the compounds that are beneficial for health.

\subsection{Aromatic compounds}

The results of the aromatic compounds examination can be found in Table 1.

Volatile aromatic compounds was kept by freeze drying, unlike hot-air and combined MVD methods. By comparing these two methods, it is concluded that MVD samples contained larger amount of less volatile components. The amount of hexil-2-methylbutyrate, which has relative high boiling temperature was almost three times more in freeze dried samples than MVD samples, and more than ten times more than in hotair dried samples.

The unknown compound with 18,774 s retention time is probably a furan derivative, related to heat treatment. Thus can't be found in freeze dried samples, while in the other two higher temperature related methods' samples, detectable quantity was measured.

The woody, sweet-scented alpha-farnezene carbohydrate had a detectable quantity only in the combined MVD samples.

By a sense of smell over the samples', the freeze dried samples had the most intensive smell, related to a high amount of volatile components. The MVD samples had a mild caramel scent due to the Maillard reaction.

\subsection{Hardness measurement}

Fig. 2 shows the resistive force of the dried products against compression length. The apple product dried with combined MVD is hard and rigid. Due to the compression the samples

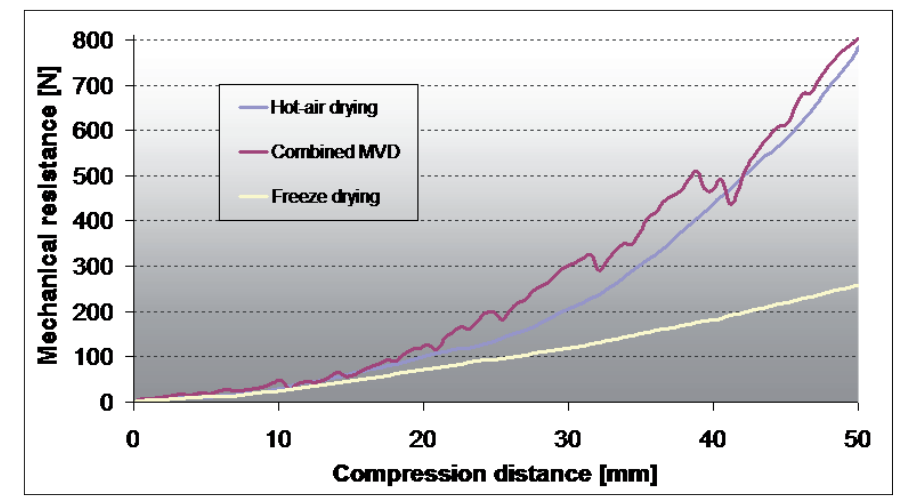

Fig. 2. Hardness of dried samples

occasionally cracked, causing sudden decrease of its velocity and the resistive force against the adapter. Hence the breaking points in the curve, which can't be found at the other two methods' curves. The hot-air dried and freeze dried samples' curves are steadily increasing. The hot-air dried ones are hard but elastic and have small volume. The freeze dried samples have soft consistency and less elastic, therefore their resistive force is significantly lower.

\subsection{Organoleptic properties}

For the appearance and the color, the freeze dried samples scored the highest followed by the combined MVD then the hot-air dried ones. The shape and color of the freeze dried samples most closely match the fresh apples. The combined MVD samples are a bit darker and have a bit lower bulk volume. The hot-air dried samples are the most dark and concise ones. As for the consistency and taste, the combined MVD samples were find out to be the best, due to the crispy texture and pleasant flavor. The evaluators resembled the freeze dried samples to puffed soft candy and the hot-air dried sampled was told hard to chew. The appearance was not an important factor for most of the evaluators, therefore the most consuming preferred sample was the combined microwave vacuum dried product (Fig. 3) 


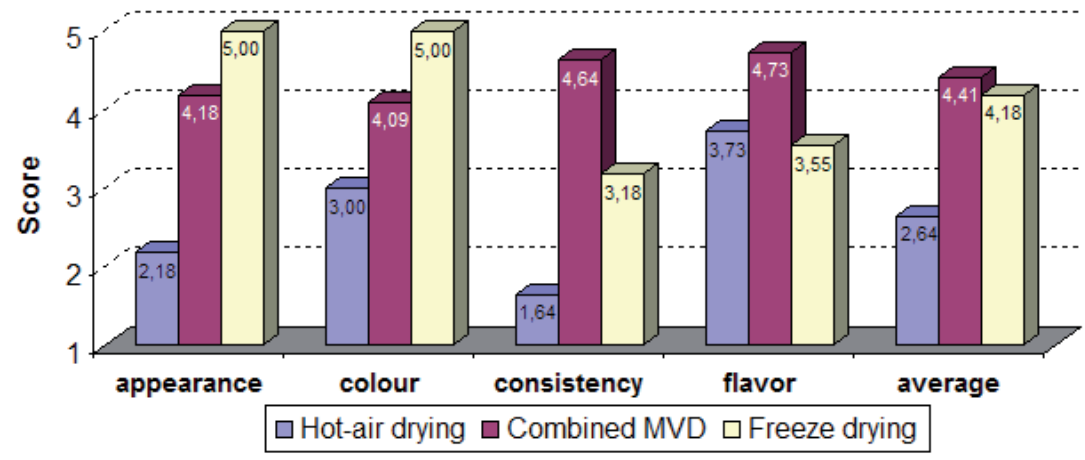

Fig. 3. Organoleptic properties of dried samples

\subsection{Microbiological examination}

The examination showed that all of the samples' plate counts are at or below detection limit. The water activity of the samples is low enough that no significant microbial growth is expected (Tab. 2).

\section{Conclusions}

By the results from drying experiments with apples, it was successfully shown that combined microwave vacuum drying with hot-air drying is capable of creating a puffed crunchy product with more preferred sensory properties, than the dried products made with hot-air drying, or freeze drying. Moreover this preference, the product contains notable aromatic compounds, significantly more phenolic compounds and not significantly the highest antioxidant capacity, than the other two products. With proper, vapor-impermeable packing it has long shelf life due to microbiological stability. These properties make the combined microwave vacuum drying a strong competitor to hot-air dried or freeze dried products in many areas of food manufacturing.
Tab. 2. Microbiological examination

\begin{tabular}{cccc}
\hline $\begin{array}{c}\text { samples } \\
\text { Microbes }\end{array}$ & $\begin{array}{c}\text { Hot-air drying } \\
\text { [cfu/g] }\end{array}$ & $\begin{array}{c}\text { freeze drying } \\
\text { [cfu/g] }\end{array}$ & $\begin{array}{c}\text { Combined } \\
\text { MVD [cfu/g] }\end{array}$ \\
\hline $\begin{array}{c}\text { Aerobic plate } \\
\text { count }\end{array}$ & $<10$ & $10^{3}$ & $<10$ \\
Fungi & $<10$ & $2 \times 10^{2}$ & $<10$ \\
Yeast & $<10$ & $<10$ & $<10$ \\
Coliforms & $<10$ & $<10$ & $<10$ \\
E. coli & $<10$ & $<10$ & $<10$ \\
Salmonella & $<1 / 25$ & $<1 / 25$ & $<1 / 25$ \\
Lysteria & $<1 / 25$ & $<1 / 25$ & $<1 / 25$ \\
onocytogenes & & & $0,196 \pm 0,002$ \\
Water activity & $0,272 \pm 0,011$ & $0,233 \pm 0,001$ & \\
[-] & & & \\
\hline
\end{tabular}

\section{References}

1 Chang C-H., Lin H-Y., Chang C-Y., Liu Y-C., Comparisons on the antioxidant properties of fresh, freeze-dried and hot-air-dried tomatoes. Journal of Food Engineering, 77 (3), pp. 478-485, (2006). DOI: $10.1016 /$ j.jfoodeng.2005.06.061

2 Clary C. D., Wang S. J., Petrucci, V. E., Fixed and Incremental Levels of Microwave Power Application on Drying Grapes under Vacuum. Journal of Food Science, 70 (5), pp. E344-E349, (2005). DOI: 10.1111/j.1365-2621.2005.tb09975.x

3 Durance T. D., Wang J. H., Energy Consumption, Density, and Rehydration Rate of Vacuum Microwave- and Hot-Air Convectiondehydrated Tomatoes. Journal of Food Science, 67 (6), pp. 2212-2216, (2002). DOI: 10.1111/j.1365-2621.2002.tb09529.x

4 Ferenczi S., Czukor B., Cserhalmi Zs., Combined air-and microwave-vacuum drying I. [In Hungarian: Légárammal kombinált mikrohullámú vákuumszáritás I.] Élelmiszer Tudomány Technológia, 64 (3), pp. 15-22, (2010). 
9 Martínez-Las Heras R., Heredia A., Castelló M. L., Andrés A., Influence of drying method and extraction variables on the antioxidant properties of persimmon leaves. Food Bioscience, 6, pp. 1-8, (2014). DOI: 10.1016/j.fbio.2014.01.002

10 Mitra P., Meda V., Optimization of Microwave-Vacuum Drying Parameters of Saskatoon Berries Using Response Surface Methodology. Drying Technology, 27 (10), pp. 1089-2009, (2009). DOI: $\underline{10.1080 / 07373930903221101}$

11 Singleton V. L., Rossi J. A. Jr., Colorimetry of Total Phenolics with Phosphomolybdic-Phosphotungstic Acid Reagents. American Journal of Enology and Viticulture, 16 (3), pp. 144-158, (1965).

12 Scaman H. C., Durance T. D., Combined Microwave Vacuum-drying. In. Sun D-W. (ed.), Emerging Technologies for Food Processing. Academic Press, (2005). DOI: $10.1016 /$ B978-012676757-5/50021-9

13 Song X., Zhang M., Mujumdar A. S., Fan L., Drying Characteristics and Kinetics of Vacuum Microwave-Dried Potato Slices. Drying Technology: An International Journal, 27 (9), pp. 969-974, (2009). DOI: $\underline{10.1080 / 07373930902902099}$
14 Therdthai N., Zhou W., Characterization of microwave vacuum drying and hot air drying of mint leaves (Mentha cordifolia Opiz ex Fresen). Journal of Food Engineering, 91 (3), pp. 482-489, (2009). DOI: $10.1016 /$ j.jfoodeng.2008.09.031

15 Yamaguchi T., Takamura H., Matoba T., Terao J., HPLC Method for Evaluation of the Free Radical-scavenging Activity of Foods by Using 1,1-diphenyl-2-picrylhydrazyl. Bioscience, Biotechnology, and Biochemistry, 62 (6), pp. 1201-1204, (1998).

DOI: $10.1271 / \mathrm{bbb} .62 .1201$

16 Zhang M., Li C. L., Ding X. L., Effects of Heating Conditions on the Thermal Denaturation of White Mushroom Suitable for Dehydration. Drying Technology: An International Journal, 23 (5), pp. 1119-1125, (2005). DOI: $\underline{10.1081 / D R T-200059145}$

17 Zhang M., Tang J., Mujumdar A. S., Wang S., Trends in microwave-related drying of fruits and vegetables. Trends in Food Science \& Technology, 17 (10), pp. 524-534, (2006). DOI: $10.1016 / \mathrm{j}$. tifs.2006.04.011 